\title{
Effect of socioeconomic characteristics and lifestyle on BMI distribution in the Chinese population: a population-based cross- sectional study
}

Weihua Wang ${ }^{1}$, Lin Qiu', Rina Sa', Shaonong Dang ${ }^{2}$, Feng Liư ${ }^{1 *}$ and Xiang Xiao ${ }^{3}$

\begin{abstract}
Background: Body mass index (BMI) is an accepted measurement that is widely used to quantify overweight and obesity at the population level. Previous studies have described the distribution variation of BMI through applying common statistical approaches, such as multiple linear or logistic regression analyses. This study proposed that associations between BMI and socioeconomic characteristics, diet, and lifestyle factors varied across the conditional BMI distribution.

Methods: This study was based on a sample of 10,023 Chinese adults who participated in the monitoring of chronic diseases and associated risk factors in Shaanxi Province, Northwest China, in 2013. Cross-quantile factors were observed in the relationships between major risk factors and BMI through quantile regression (QR) and ordinary least squares (OLS) regression.

Results: Participants' mean BMI was $24.19 \pm 3.51 \mathrm{~kg} / \mathrm{m}^{2}$ (range $14.33-52.82 \mathrm{~kg} / \mathrm{m}^{2}$ ). The QR results showed that living in urban areas was associated with BMI in the low and central quantiles (10th-60th). Participants with 6-9 years of education were $0.23-0.38 \mathrm{BMI}$ units higher in the first half of the BMl quantiles compared with those with $\leq 6$ years of education. There was a positive association between consumption of red meat and BMl; however, the association diminished from the 10th to the 50th quantile. Intake of oil and alcohol were positively associated with all BMI quantiles. Cigarette smoking per day was negatively associated with BMI, which showed a U-shaped distribution. The above results were also observed in the OLS.
\end{abstract}

Conclusion: This study implies that in addition to socioeconomic characteristics, limiting oil and alcohol intake may decrease BMI score. Consuming more red meat could be a strategy to increase BMI.

Keywords: Body mass index, Socioeconomic characteristics, Quantile regression, Lifestyle factors

\footnotetext{
*Correspondence: myjshy@163.com

'Department of Chronic Disease Control and Prevention, Shaanxi Provincial

Center for Disease Control and Prevention, No. 3, Jiandong Road, Xi'an,

People's Republic of China

Full list of author information is available at the end of the article
}

C C The Author(s). 2021 Open Access This article is licensed under a Creative Commons Attribution 4.0 International License, which permits use, sharing, adaptation, distribution and reproduction in any medium or format, as long as you give appropriate credit to the original author(s) and the source, provide a link to the Creative Commons licence, and indicate if changes were made. The images or other third party material in this article are included in the article's Creative Commons licence, unless indicated otherwise in a credit line to the material. If material is not included in the article's Creative Commons licence and your intended use is not permitted by statutory regulation or exceeds the permitted use, you will need to obtain permission directly from the copyright holder. To view a copy of this licence, visit http://creativecommons.org/licenses/by/4.0/ The Creative Commons Public Domain Dedication waiver (http://creativecommons.org/publicdomain/zero/1.0/) applies to the data made available in this article, unless otherwise stated in a credit line to the data. 


\section{Background}

The average body mass index (BMI) has increased worldwide in the past two decades, especially in low- and middle-income countries [1-4]. It is known that obesity defined by BMI is a risk factor for multiple noncommunicable chronic diseases, such as cancer and cardiovascular disease, which places an increasing burden on healthcare systems $[5,6]$. The global number of deaths caused by non-communicable chronic diseases is expected to rise from 59 to $69 \%$ between 2002 and 2030 [7, 8].

With the rapid social and economic development in China, BMI distribution curves moved to the right from 1981 to 2011, with an increasing prevalence of overweight and obesity in the Chinese population [3, 9]. The prevalence of obesity among Chinese adults more than doubled in the last three decades [10], and about $46 \%$ of Chinese adults are obese or overweight [11]. Although many studies have focused on obesity in China, there are noticeable demographic and socioeconomic disparities given the wide variation in China [12]. Behaviors such as tobacco smoking, alcohol intake, and physical activity have also been shown to be associated with individual weight gain or loss [13-15]. Most previous studies that examined the effect of health behaviors on changes in BMI used either multiple linear or logistic regression analyses, which do not capture distribution variations in different BMI quantiles [16-18]. Therefore, the former methods may mask some important relations in various quantiles of BMI distribution. In contrast, it has been suggested that quantile regression (QR) is a useful method to address important differences across the overall BMI distribution [19], and is more robust against skewness or outliers than traditional linear regression. Given that the effect of risk factors may vary by BMI distribution, we aimed to examine the effects of socioeconomic status, lifestyle factors, and other factors on different BMI status by QR. This enabled us to observe the effect of risk factors on BMI ranging from low to high quantiles along the entire BMI distribution.

\section{Methods}

\section{Study setting}

Shaanxi Province is located in Northwest China. It consists of three regions: Northern, Central, and Southern Shaanxi. Shaanxi is a less developed province in terms of socioeconomic factors compared with Eastern China. The provincial gross domestic product in 2019 was 365 billion US dollars, which was estimated in the middle of the 31 provincial regions in China [20]. The resident population of Shaanxi Province was 37.9 million people [21].

\section{Study design and sampling}

Shaanxi Center for Disease Control and Prevention has implemented the monitoring of chronic diseases and associated risk factors every 3 years since 2004, as detailed in the China Chronic Disease Prevention and Control Work Plan. Because of the largest sample size of all surveys from 2004 to 2018, this study was based on data collected in 2013, which covered 17 monitoring points (counties or districts) with 10,300 participants recruited in Shaanxi Province. The target subjects were Chinese people aged 18 years and above who had lived for more than 6 months in their current residence. Participant recruitment was conducted by stratified multistage sampling. In the first stage of sampling, 10 counties were selected from Shaanxi Province using the method of probability proportional to size. In the second stage of sampling, four townships were selected in each selected county using the same method. In the third stage of sampling, three villages were selected from each selected township using the same method. In the fourth stage of sampling, at least 50 households were randomly selected from the selected villages. In the final stage of sampling, one adult aged 18 years and above was randomly selected from each household. A total sample of 10,320 participants was required, assuming an overweight prevalence of $30.6 \%$ in the study population, a relative error of $15 \%$, $\mathrm{a}=0.05$, design effect $=2.0, \mathrm{~N}=\operatorname{deff} \mu_{\alpha}^{2} \frac{\mathrm{P}(1-\mathrm{P})}{\mathrm{d}^{2}}$, and accounting for an expected $10 \%$ non-response rate [22].

\section{Ethics statement}

The National Health and Family Planning Commission (NHFPC, previously the Ministry of Health) of China and the Ethics Committee of the Chinese Center for Disease Control and Prevention approved the program. An informed consent form was completed by all participants.

\section{Quality control}

Interviewers in this study were staff from local CDC and healthcare institutes. Passing a test after training was mandatory before staff conducted the survey. The test aimed to examine each interviewer's familiarity with the questionnaires, operation standards, and measurement of height, weight, blood pressure, and precautions for blood draw. Anthropometric measurements were standardized before the survey. A checking system that comprised checking in the field by interviewers themselves, officials from the local CDC, and supervisors from the workgroup was applied to control the quality of this study. Personnel from local healthcare institutes and health offices helped organize the field investigation and explained the study procedures to participants. Participants with cognitive problems, language problems, mental disorders, or severe diseases were excluded. Recruited participants were interviewed twice if logical inconsistencies and missing values were detected. 


\section{Measures}

Questionnaires were used to obtain information about participants' demographic characteristics, dietary habits, lifestyle behaviors, disease history, and health status through face-to-face interviews conducted by trained local CDC staff. The questionnaire that was used in the survey was drafted by the China CDC and its reliability and validity were verified. Participants' height was measured without shoes in meters to the nearest millimeter (Wuxi Weigher Factory Co., Ltd., Model TZG, precision $1 \mathrm{~mm})$. Weight was measured by an electronic scale (TANITA Corporation, HD-390, precision $100 \mathrm{~g}$ ) when participants were barefoot and bareheaded with only light clothes. Blood pressure, fasting, and postprandial blood samples were also tested. Details of this monitoring have been described elsewhere [22].

BMI $\left(\mathrm{kg} / \mathrm{m}^{2}\right)$ was calculated as weight in kilograms divided by the height in meters squared. Covariates were as follows. (1) Demographic characteristics including three areas in Shaanxi province, age of participants and education years (total years of schooling); (2) Dietary habits including consumption of red meat, fresh vegetables and fruits, oil, and salt. To assess the intake of red meat, fresh vegetables, and fruits, participants were first asked whether they had eaten the food or not in the last 12 months. If the answer was yes, then the frequency (year, month, week, or day) and amount (g) of each serving was collected. The daily consumption of the above foods was estimated by multiplying the frequency and amount of each time. The daily intake of oil and salt was estimated by the amount of each item a household consumed per day divided by the number of people in the family. (3) Lifestyle factors included cigarette smoking and alcohol intake. Cigarette smoking was defined as a participant who smoked every day during the monitoring period, and alcohol intake as consuming alcohol from any alcoholic beverages (beers or wines) every day, which was collected in the same way as dietary habits. (4) Physical activity including activity at work, during commuting, and in leisure time was divided into three categories (low, moderate, high) according to the Global Physical Activity Questionnaire Analysis Guide.

\section{Statistical analysis}

Initially, BMI and baseline data were reported as mean \pm standard deviation and median (25th $\sim 75$ th percentile) for normally and non-normally distributed continuous variables, respectively. They were also tested by t-tests (normally distributed data between two groups), analysis of variance (normally distributed data between three or more groups), or Kruskal-Wallis tests (not-normally distributed data among groups). Categorical variables were described by counts and proportions and examined by $\chi^{2}$ tests among groups. The skewness, kurtosis, and normality of BMI were also tested. To determine risk factors potentially associated with BMI distribution, we used QR. Linear regression based on the ordinary least squares (OLS) was used to explain the effects of risk factors on the mean value of BMI. QR could provide a detailed description of the effects on the BMI at any point along its distribution. The choice of BMI percentiles mainly depends on the research objectives and the distribution of the outcome. Nine BMI quantiles of were selected (from 10th to the 90th), step by 10th based on the lowest to the highest BMI value. Coefficients of regression for each quantile were computed and their significance was tested. Multivariate QR models, including demographic characteristics (area, age, sex, and education), dietary habits (red meat, fresh vegetables, and fruits), lifestyle factors (cigarette smoking and alcohol intake), and physical activities, were conducted for each BMI quantile. Coefficients of OLS were also estimated as comparisons. All statistical analyses were performed using $\mathrm{R}$ 3.3.1. $P$-values $<0.05$ were considered statistically significant in this study.

\section{Results}

\section{Baseline data for participants}

A total of 10,023 out of 10,320 (97.12\%) participants were included in the statistical analyses. Among these, $52.25 \%$ of males and $53.49 \%$ of females were from urban areas, and $57.31 \%$ of males and $60.26 \%$ of females were from Central Shaanxi. More females (47.11\%) had attained $\leq 6$ years of education compared with males (33.57\%) $\quad\left(\chi^{2}=192.26, \quad P<0.001\right)$. Male participants consumed more red meat $\left(\chi^{2}=14.184, P<0.001\right)$ and alcohol $\left(x^{2}=34.101, P<0.001\right)$ than females, but they showed no difference in consumption of vegetables, fruits, salt, and oil (Table 1).

\section{BMI in Shaanxi Province}

The mean BMI of participants was $24.19 \pm 3.51 \mathrm{~kg} / \mathrm{m}^{2}$, and the range was $14.33 \mathrm{~kg} / \mathrm{m}^{2}$ to $52.82 \mathrm{~kg} / \mathrm{m}^{2}$. The $25 \mathrm{th}$, 50th, and 75th percentiles of BMI were $21.68 \mathrm{~kg} / \mathrm{m}^{2}$, $23.92 \mathrm{~kg} / \mathrm{m}^{2}$, and $26.31 \mathrm{~kg} / \mathrm{m}^{2}$, respectively. Statistics for skewness and kurtosis were 0.70 and 1.75 , respectively. The normality test showed BMI did not have a normal distribution (Fig. 1). The average BMI of female participants, participants living in urban areas, and participants living in Central Shaanxi were higher than their male, rural, and non-Central Shaanxi counterparts $(P<0.001)$ (Table 2).

\section{Risk factors for BMI}

To determine the potential risk factors for the BMI distribution, multivariate QR analyses of BMI were conducted. Of the covariates associated with all BMI quantiles, age showed a slightly diminished positive 
Table 1 Participants' sociodemographic characteristics ( $n$ (\%) or mean \pm SD)

\begin{tabular}{|c|c|c|c|c|}
\hline & $\begin{array}{l}\text { Male } \\
N=4612(45.37)\end{array}$ & $\begin{array}{l}\text { Female } \\
N=5554(54.63)\end{array}$ & $t / x^{2}$ & $P$ \\
\hline Residence (urban) & $2410(52.25)$ & $2971(53.49)$ & 1.55 & 0.213 \\
\hline \multicolumn{5}{|l|}{ Areas } \\
\hline North & 927(20.10) & $867(15.61)$ & 35.04 & $<0.001$ \\
\hline Central & $2643(57.31)$ & $3347(60.26)$ & & \\
\hline South & 1042(22.59) & $1340(24.13)$ & & \\
\hline Age & $49.70 \pm 14.63$ & $49.40 \pm 13.97$ & 1.06 & 0.29 \\
\hline \multicolumn{5}{|l|}{ Education } \\
\hline$\leq 6$ years & 1546(33.57) & 2612(47.11) & 192.26 & $<0.001$ \\
\hline$>6$ years $\& \leq 9$ years & 2704(58.72) & $2621(47.28)$ & & \\
\hline$>9$ years & $355(7.71)$ & $311(5.61)$ & & \\
\hline Fresh vegetable/fruit & $533.98 \pm 444.70$ & $524.65 \pm 408.08$ & 1.10 & 0.27 \\
\hline Red meat & $49.20 \pm 96.55$ & $26.70 \pm 52.24$ & 14.18 & $<0.001$ \\
\hline Salt & $9.53 \pm 8.15$ & $9.69 \pm 7.96$ & -0.97 & 0.33 \\
\hline Oil & $56.77 \pm 31.71$ & $57.87 \pm 31.39$ & -1.55 & 0.12 \\
\hline alcohol & $35.25 \pm 60.35$ & $3.88 \pm 17.63$ & 34.10 & $<0.001$ \\
\hline Smoking everyday & $2323(50.37)$ & $55(0.99)$ & 3428.31 & $<0.001$ \\
\hline \multicolumn{5}{|l|}{ Physical activity } \\
\hline Light & $824(17.87)$ & $897(16.15)$ & 12.24 & 0.002 \\
\hline Moderate & 1095(23.74) & $1470(26.47)$ & & \\
\hline High & 2693(58.39) & $3187(57.38)$ & & \\
\hline
\end{tabular}

SD Standard deviation

association from head to tail of the BMI quantiles. Consumption of oil and alcohol were also positively associated with all BMI quantiles. Cigarette smoking each day was negatively associated with all BMI quantiles and the relationship was $U$-shaped. Compared with light physical activity, high physical activity was least associated with BMI in the 60th quantile. Some risk factors were associated with parts of BMI quantiles. Compared with participants in rural areas, those in urban areas were associated with BMI in low and central quantiles (10th-60th). Females were 0.273-0.594 BMI units higher than males from the center (50th quantile) to the tail (90th quantile) of the BMI quantiles. Participants with 6-9 years of education were 0.23-0.38 BMI units higher for first half of the BMI quantiles compared with those with $\leq 6$ years of education. The positive correlation between red meat and BMI diminished from the 10th to the 50th quantile. OLS analysis found similar results for average BMI (Table 3, Fig. 2).

\section{Discussion}

In this study, our QR analysis showed that residence, area, sex, education, and red meat were associated with some quantiles of BMI score. Age, oil, alcohol, smoking, and physical activity were associated with all BMI quantiles. Urban residents tended to have larger scores than rural residents in the central BMI quantiles. Consumption of oil and alcohol were positively associated with BMI throughout the quantiles. Daily cigarette smoking was only negatively associated with BMI. These findings indicated the potential factors that affected the BMI of residents in Northwest China, and suggested in which quantiles of BMI these factors could have an effect.

Sociodemographic factors were found to affect the conditional BMI distribution in previous studies. Evidence from less-developed countries suggested that rural residents weighed less than their urban counterparts [2, 23]. In China, the BMI of residents in urban areas was also higher than that of those in rural areas [24, 25]. These findings agreed with the findings of the present study, but were inconsistent with research from developed countries, in which an inverse association between socioeconomic status and weight was reported [26-28]. A study involving migrants in India reported that there was a rapid increase of adiposity after migrating from rural to urban areas [29]. The higher BMI in urban areas in less developed countries and in rural areas in developed countries may be the result of higher individualand community-level socioeconomic status. It has been suggested that other factors may cause increased body weight in Northwest China. In this study, sex only played a role at the upper tail of BMI (50th-90th 


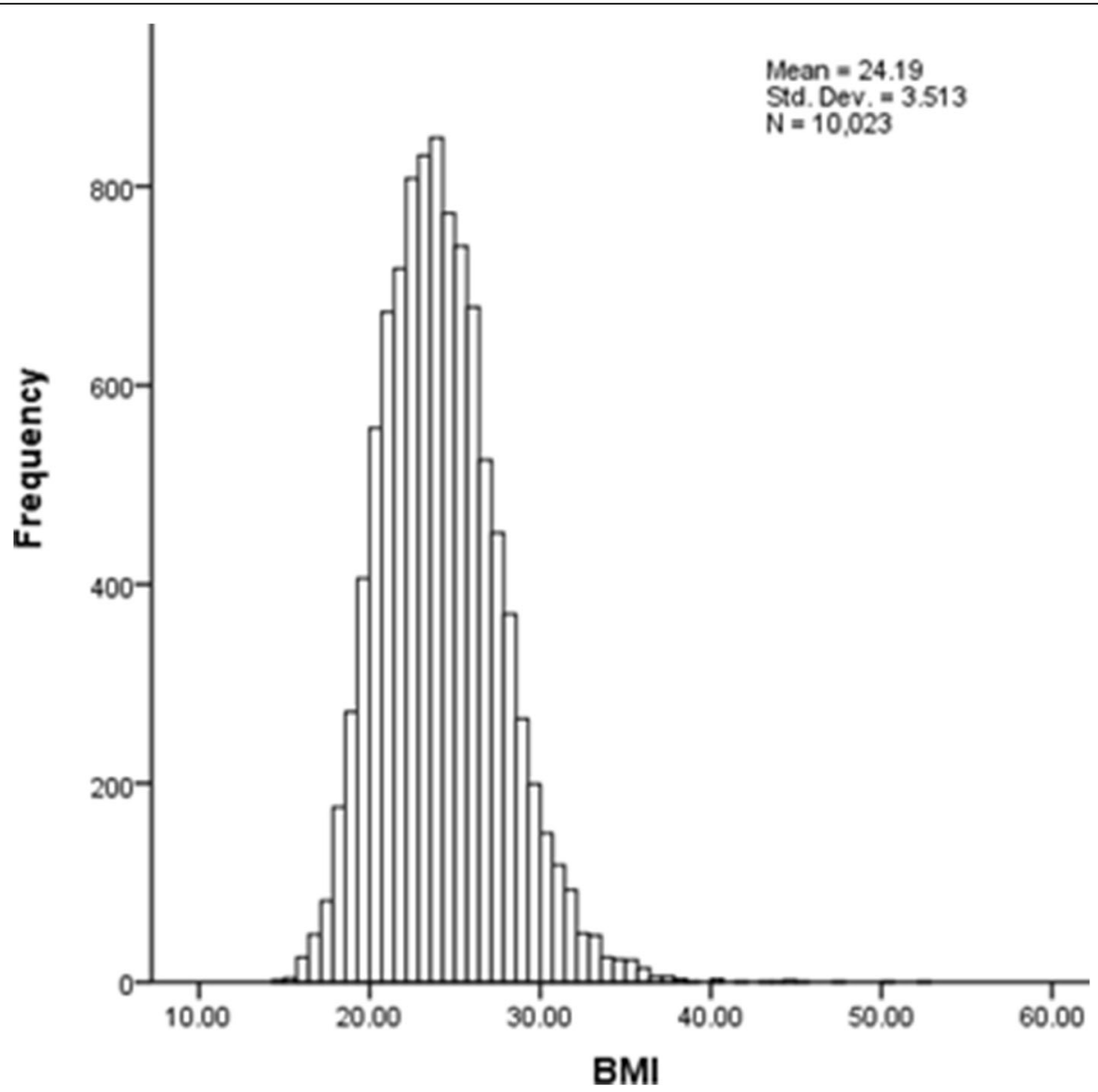

Fig. 1 Histogram of BMI in Shaanxi Province. Mean $=24.19$ Std $\cdot$ Dev $=3.513 \mathrm{~N}=10,023$

Table 2 BMl distribution in different socio-demographic characteristics

\begin{tabular}{|c|c|c|c|c|c|c|}
\hline & Mean \pm SD & median(25 75percentile) & floor & celling & $x^{2} / F$ & $P$ \\
\hline \multicolumn{7}{|l|}{ Residence } \\
\hline Rural & $24.00 \pm 3.55$ & $23.71(21.49 \sim 26.14)$ & 14.33 & 50.07 & 29.466 & $<0.001$ \\
\hline Urban & $24.35 \pm 3.48$ & $24.08(21.91 \sim 26.43)$ & 15.63 & 52.82 & & \\
\hline \multicolumn{7}{|l|}{ Areas } \\
\hline North & $23.88 \pm 3.53$ & $23.51(21.29 \sim 26.05)$ & 14.33 & 52.82 & 43.596 & $<0.001$ \\
\hline Central & $24.37 \pm 3.58$ & $24.11(21.88 \sim 26.49)$ & 15.31 & 50.07 & & \\
\hline South & $23.96 \pm 3.28$ & 23.73(21.6 25.96) & 15.64 & 40.03 & & \\
\hline \multicolumn{7}{|l|}{ Gender } \\
\hline Male & $24.00 \pm 3.36$ & $23.8(21.62 \sim 26.08)$ & 14.33 & 52.82 & 15.795 & $<0.001$ \\
\hline Female & $24.34 \pm 3.63$ & $24.03(21.73 \sim 26.45)$ & 14.78 & 50.07 & & \\
\hline \multicolumn{7}{|l|}{ Education } \\
\hline$\leq 6$ years & $24.15 \pm 3.53$ & $23.87(21.66 \sim 26.19)$ & 14.33 & 45.05 & 1.307 & 0.520 \\
\hline$>6$ years $\& \leq 9$ years & $24.22 \pm 3.5$ & $23.95(21.7 \sim 26.4)$ & 15.63 & 50.07 & & \\
\hline$>9$ years & $24.15 \pm 3.47$ & $23.98(21.82 \sim 26.2)$ & 16.13 & 52.82 & 3.327 & 0.190 \\
\hline \multicolumn{7}{|l|}{ Physical activity } \\
\hline Light & $24.08 \pm 3.67$ & $23.83(21.49 \sim 26.14)$ & 15.31 & 44.23 & & \\
\hline Moderate & $24.18 \pm 3.64$ & $23.91(21.52 \sim 26.37)$ & 15.63 & 52.82 & & \\
\hline High & $24.22 \pm 3.41$ & $23.95(21.81 \sim 26.3)$ & 14.33 & 50.07 & & \\
\hline
\end{tabular}




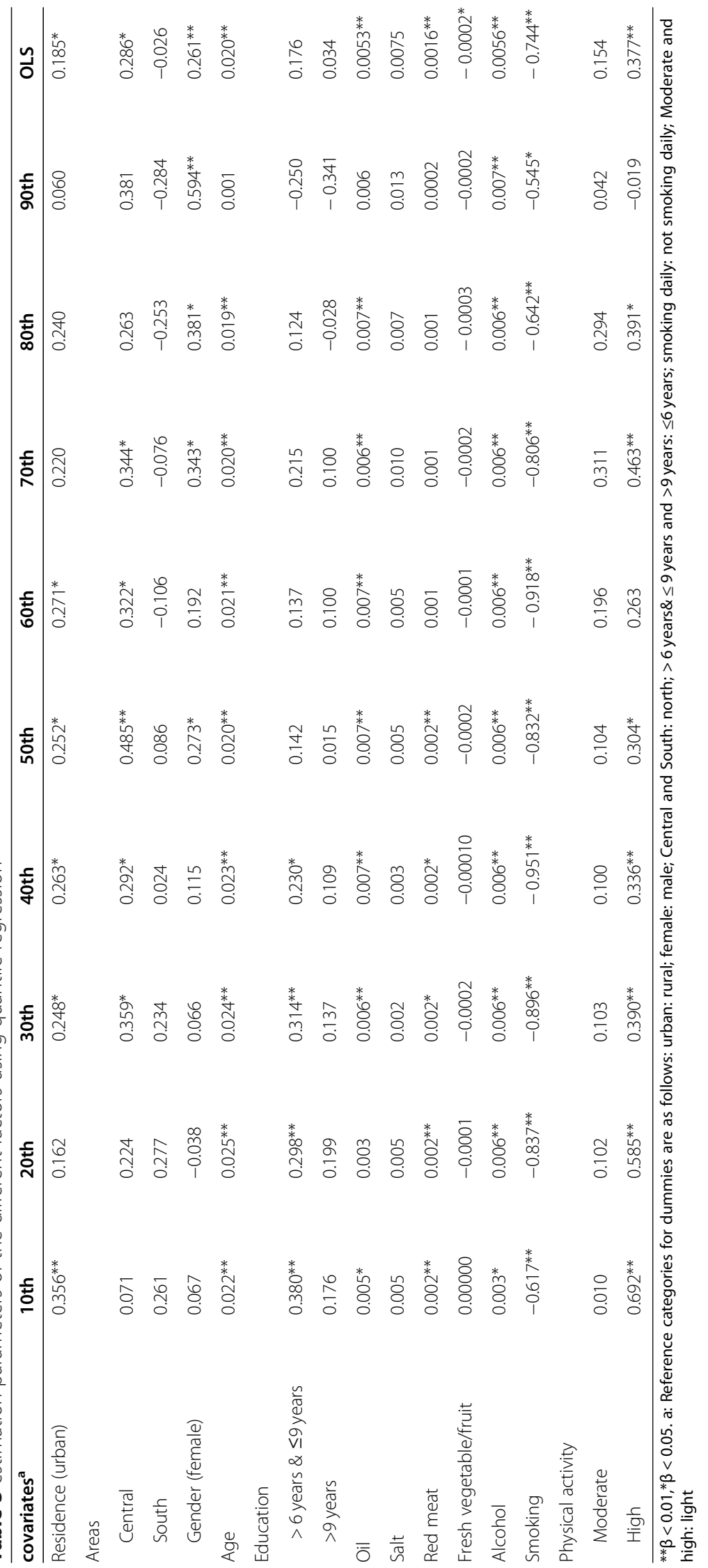



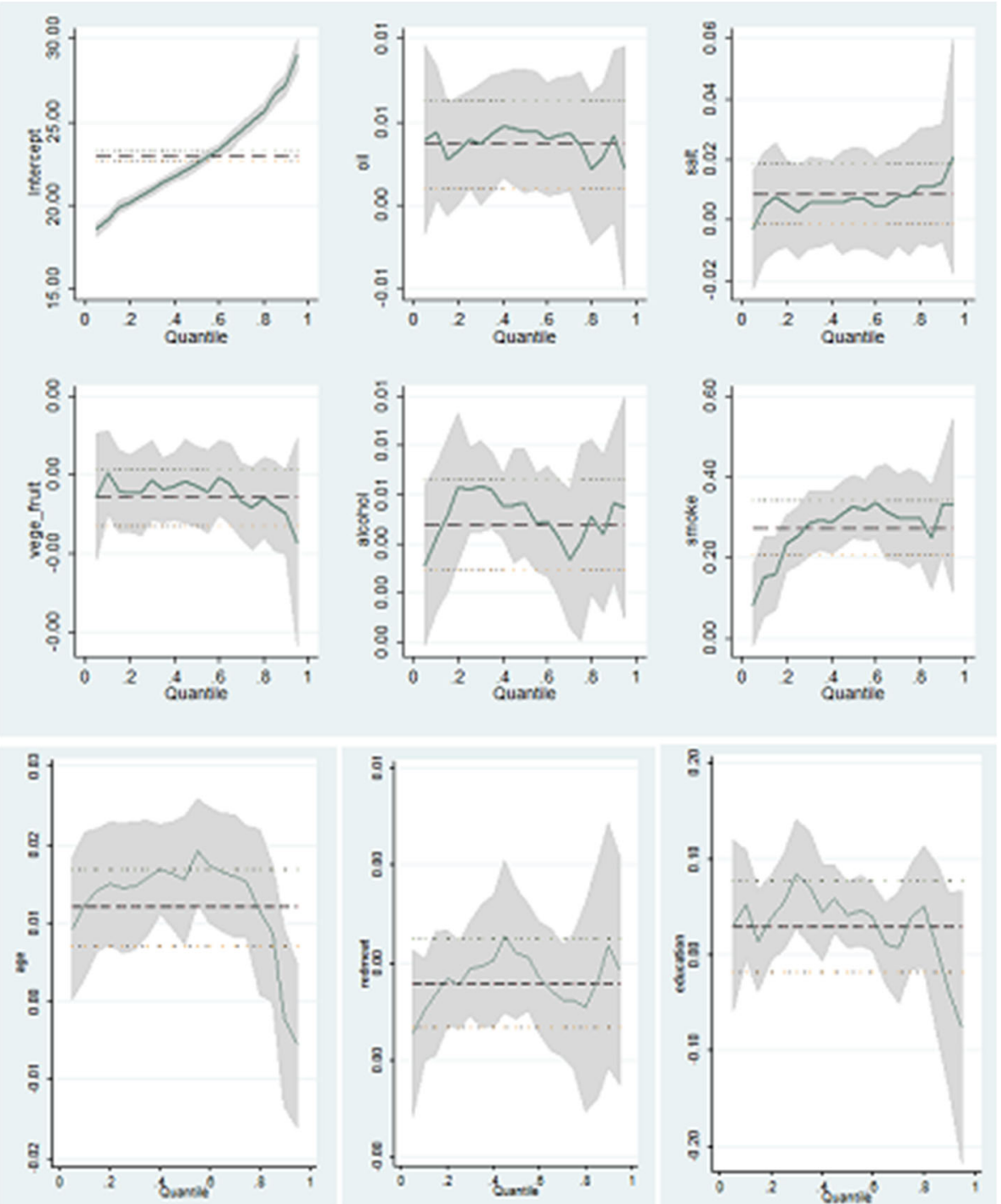

Fig. 2 Quantile regression estimates of different variables* The shaded areas around the regression estimates are the $95 \%$ confidence intervals. The thick dashed line is the ordinary least squares (OLS) estimate, and the dotted lines show the OLS 95\% confidence interval

quantile) with females' BMI higher than that of males, which was consistent with research by Mascietaylor and Beydoun [30, 31]. The BMI of older participants was higher in most BMI quantiles (10th-80th), which suggests public health intervention for overweight and obesity could target the senior population.

The association between diet and BMI has been well studied [32-34]. In this study, we found oil was positively associated with BMI across quantiles. Fresh vegetables, fruits, and salt showed no association with BMI. The statistical insignificance of fresh vegetables and fruits consumption may be unexpected since the higher consumption of fiber-rich food was supposed to be related to lower BMI. However, our QR model included red meat intake, oil consumption, and salt intake. These variables were already controlled for in the main pathway through which vegetables and fruits may influence BMI, contributing to the lack of statistical significance of fiber-rich food.

Alcohol intake was positively associated with the increase of BMI, while daily cigarette smoking had a negative association with BMI quantiles. Similar findings have been shown in studies that reported increasing rates of obesity will be observed if subjects quit smoking [35]. Our QR results showed that the effect of smoking status largely influenced BMI under the 80th percentile, whereas the upper conditional tail of the BMI distribution remained unaffected [36]. The genes relationship or molecular mechanism remains unknown, but a previous study in China showed that smoking was significantly 
associated with the belief that smoking played an important role in weight control, which could contribute to the understanding of the effect of smoking on BMI quantiles in the Chinese population [37].

There were some limitations in our study. First, we must be cautious in extrapolating the study results to the whole Chinese population as the data are representative of Shaanxi Province. Second, independent variables in this analysis should only be viewed as associated with BMI because this study used a cross-sectional design and cannot make casual inferences. A longitudinal study may be necessary to infer causality. Third, recall bias might have influenced the results, as all information except weight and height were self-reported. Finally, we used data from 2013, and obesity and its risk factors in China are still changing; therefore, an updated study should continue to focus on these associations among Chinese adults.

\section{Conclusion}

Given the shift of BMI distribution, it is not appropriate to examine the whole BMI distribution with means or medians. Instead, methods that could capture the conditional BMI distribution are necessary. This study found that urban residents tended to have a higher BMI score. With the increase of participants' age, BMI also increased. Education of around 6-9 years and red meat consumption played a positive role only in the first half of the BMI quantiles. With the increased intake of oil and alcohol, BMI increased throughout the quantiles. Smoking daily was the only factor with an inverse association.

\section{Abbreviations}

QRs: Quantile regressions; OLS: Ordinary least squares; BMI: Body mass index

\section{Acknowledgments}

We thank the residents that participated in our study. We thank the Minster of Health, Shaanxi Province, as well as officials at the municipality and county levels for support and cooperation. We also thank the CDCs at the municipality and county levels for cooperation and organization in the field data collection, and staff from the Shaanxi CDC for participation in the field data collection and surveillance. We thank Audrey Holmes, MA, from Liwen Bianji (Edanz) (www.liwenbianji.cn/) for editing the English text of a draft of this manuscript.

\section{Authors' contributions}

WH drafted the manuscript and preformed the statistical analyses. LQ, RS, and SD contributed to planning the design of the study, data collection, and monitoring the participants. FL contributed to planning the design of the study. XX drafted and revised the manuscript. All authors read and approved the final manuscript.

\section{Funding}

This research received no specific grant from any funding agency in the public, commercial, or not-for-profit sectors.

\section{Availability of data and materials}

The datasets used and analyzed during the present study are available from the corresponding author on reasonable request.

\section{Declarations}

Ethics approval and consent to participate

All enrolled participants in the monitoring program gave written informed consent for participation. The Ethics Committee of the Chinese Center for Disease Control and Prevention approved the implementation of the program.

Consent for publication

Not applicable.

\section{Competing interests}

The authors declare that they have no competing interests.

\section{Author details}

${ }^{1}$ Department of Chronic Disease Control and Prevention, Shaanxi Provincial Center for Disease Control and Prevention, No. 3, Jiandong Road, Xi'an, People's Republic of China. ${ }^{2}$ Department of Epidemiology and Biostatistics, School of Public Health, Xi'an Jiaotong University Health Science Center, Xi'an, People's Republic of China. ${ }^{3}$ School of Public Health, University of Alberta, Edmonton, Canada.

Received: 15 May 2020 Accepted: 28 June 2021

Published online: 10 July 2021

References

1. Kelly T, Yang W, Chen CS, Reynolds K, He J. Global burden of obesity in 2005 and projections to 2030. Int J Obes. 2008;32(9):1431-7. https://doi. org/10.1038/ijo.2008.102.

2. Prentice AM. The emerging epidemic of obesity in developing countries. Int J Epidemiol. 2006;35(1):93-9. https://doi.org/10.1093/ije/dyi272.

3. Wang H, Du S, Zhai F, Popkin BM. Trends in the distribution of body mass index among Chinese adults, aged 20-45 years (1989-2000). Int J Obes (Lond). 2007;31:272-8.

4. Hossain P, Kawar B, El Nahas M. Obesity and diabetes in the developing world - a growing challenge. N Engl J Med. 2007;356(3):213-5. https://doi. org/10.1056/NEJMp068177.

5. Kolb R, Sutterwala FS, Zhang W. Obesity and cancer: inflammation bridges the two. Curr Opin Pharmacol. 2016;29:77-89. https://doi.org/10.1016/j. coph.2016.07.005.

6. Jokinen E. Obesity and cardiovascular disease. Minerva Pediatr. 2015;67(1): 25-32.

7. Lopez AD, Mathers CD, Ezzati M, Jamison DT, Murray CJL. Globaland regional burden of disease and risk factors, 2001: systematic analysis of population health data. Lancet. 2006;367(9524):1747-57. https://doi.org/10.1 016/S0140-6736(06)68770-9.

8. WHO. Global burden of disease: 2004 update. Geneva, Switzerland: WHO; 2008

9. Yifei O, Huijun W, Chang SU, Wenwen DU, Jiguo ZH, Bing ZH. Changes of BMI distribution in Chinese adults from 1989 to 2011. Acta Nutrimenta Sinica. 2014;6:529-34.

10. Xi B, Liang $Y, H e T$, Reilly $K H, H u Y$, Wang $Q$, et al. Secular trends in the prevalence of general and abdominal obesity among Chinese adults, 1993-2009. Obes Rev. 2012 Mar;13(3):287-96. https://doi.org/10.1111/j.1467-789X.2011.00944X.

11. Wang $Y$, Wang $L$, Qu W. New national data show alarming increase in obesity and noncommunicable chronic diseases in China. Eur J Clin Nutr. 2017;71(1):149-50. https://doi.org/10.1038/ejcn.2016.171.

12. Hu L, Huang X, You C, Li J, Hong K, Li P, et al. Prevalence of overweight, obesity, abdominal obesity and obesity-related risk factors in southern China. PLoS One. 2017;12(9):e0183934. https://doi.org/10.1371/journal.pone. 0183934.

13. Berkel LA, Poston WSC, Reeves RS, et al. Behavioral interventions for obesity [J]. J Am Diet Assoc. 2005;105(5):35-43. https://doi.org/10.1016/j.jada.2005. 02.031.

14. Anyangwe SC, Mtonga C, Chirwa B. Health inequities, environmental insecurity and the attainment of the millennium development goals in subSaharan Africa: the case study of Zambia. Int J Environ Res Public Health. 2006;3(3):217-27. https://doi.org/10.3390/ijerph2006030026.

15. Veugelers P, Sithole F, Zhang S, Muhajarine N. Neighborhood characteristics in relation to diet, physical activity and overweight of Canadian children. Int J Pediatr Obes. 2008;3(3):152-9. https://doi.org/10.1080/17477160801970278. 
16. Bell AC, Ge K, Popkin BM. Weight gain and its predictors in Chinese adults. Int J Obes Relat Metab Disord. 2001;25:1079-86.

17. Paeratakul S, Popkin BM, Keyou G, Adair LS, Stevens J. Changes in diet and physical activity affect the body mass index of Chinese adults. Int J Obes Relat Metab Disord. 1998;22:424-31.

18. Ingegerd J, Lena MN, Stegmayr B, Boman K, Hallmans G, Winkvist A. Associations among 25-year trends in diet, cholesterol and BMl from 140,000 observations in men and women in Northern Sweden. Nutr J. 2012; 11:40.

19. Duffy ME, Rogers ML, Kennedy GA, Keel PK, Joiner TE. Examining the association between body trust and body mass index with quantile regression. Eating Weight Disord Stud Anorexia Bulimia Obes. 2019;7:1-7.

20. National Bureau of Statistics of China. National data, annual by provinces[A/ OL]. http://data.stats.gov.cn/english/easyquery.htm?cn=E0103.Accessed 28 Feb 2020.

21. Yang C, Wu L, Cai W, Zhu W, Shen Q, Li Z, et al. Current situation, determinants, and solutions to drug shortages in Shaanxi Province, China: a qualitative study. PLoS One. 2016 Oct 25;11(10):e0165183. https://doi.org/1 0.1371/journal.pone.0165183.

22. China Center for Disease Control and Prevention. Manual of new monitoring point for chronic diseases and its risk factors monitoring in China 2013. 2013.11.

23. Melissa N, Ichiro K, Steven G, Subramanian SV. Urban-rural differences in BMI in low- and middle-income countries: the role of socioeconomic status1-3. Am J Clin Nutr. 2013;97:428-36.

24. Chen TJ, Modin B, Ji CY, Hjern A. Regional, socioeconomic and urban-rural disparities in child and adolescent obesity in China: a multilevel analysis. Acta Paediatr. 2011;100:1583-9.

25. Ling $L$, Xiaorong $G$. Analysis of overweight and obesity among adults in Shaanxi Province. Chin J Public Health Manage. 2007:2:187-9 (In Chinese).

26. Guðjónsdóttir H, Halldórsson TI, Gunnarsdóttir I, Thórsdóttir I, Thorgeirsdóttir $\mathrm{H}$, Steingrímsdóttir L. Urban-rural differences in diet, BMI and education of men and women in Iceland. Laeknabladid. 2015:101(1):11-6. https://doi. org/10.17992/lbl.2015.01.06

27. Sobal J, Stunkard AJ. Socioeconomic status and obesity: a review of the literature. Psychol Bull. 1989;105(2):260-75. https://doi.org/10.1037/0033-2 909.105.2.260.

28. McLaren L. Socioeconomic status and obesity. Epidemiol Rev. 2007;29(1):2948. https://doi.org/10.1093/epirev/mxm001.

29. Shah E, Sanjay K, Liza B, Elizabeth A, Yoav B, Tanica L. The effect of rural tourban migration on obesity and diabetes in India: a cross-sectional study. PLoS Med. 2010;7:352-3.

30. CG NM, Goto R. Human variation and body mass index: a review of the universality of BMI cut-offs, gender and urban-rural differences, and secular changes. J Physiol Anthropol. 2007;26(2):109-12.

31. Beydoun MA, Wang Y. Gender-ethnic disparity in BMI and waist circumference distribution shifts in US adults. Obesity. 2009;17(1):169-76 https://doi.org/10.1038/oby.2008.492.

32. Fialkowski MK, McCrory MA, Roberts SM, Tracy JK, Grattan LM, Boushey CJ. Dietary patterns are associated with dietary recommendations but have limited relationship to BMI in the communities advancing the studies of tribal nations across the lifespan (CoASTAL) cohort. Public Health Nutr. 2012; 15(10):1948-58. https://doi.org/10.1017/S1368980012000122.

33. Golley RK, Maher CA, Olds TS. Sleep duration or bedtime? Exploring the association between sleep timing behaviour, diet and BMI in children and adolescents. Int J Obes. 2013;37(4):546-51. https://doi.org/10.1038/ijo.2012.212.

34. Thompson OM, Ballew C. Dietary pattern as a predictor of change in BMI zscore among girls. Int J Obes. 2006;30(1):176-82. https://doi.org/10.1038/sj. ijo.0803072.

35. Robb CA, Huston SJ, Finke MS. The mitigating influence of time preference on the relation between smoking and BMI scores. Int J Obes. 2008:32(11): 1670-7. https://doi.org/10.1038/ijo.2008.151.

36. Shankar B. Obesity in China: the differential impacts of covariates along the BMI distribution. Obesity. 2010;18(8):1660-6. https://doi.org/10.1038/oby.2 009.417 .

37. Ge K, Weisell R, Guo X, Cheng L, Ma H, Zhai F, et al. The body mass index of Chinese adults in the1980s. Eur J ClinNutr. 1994;48(Suppl 3):S148-54.

\section{Publisher's Note}

Springer Nature remains neutral with regard to jurisdictional claims in published maps and institutional affiliations.

Ready to submit your research? Choose BMC and benefit from:

- fast, convenient online submission

- thorough peer review by experienced researchers in your field

- rapid publication on acceptance

- support for research data, including large and complex data types

- gold Open Access which fosters wider collaboration and increased citations

- maximum visibility for your research: over $100 \mathrm{M}$ website views per year

At $\mathrm{BMC}$, research is always in progress.

Learn more biomedcentral.com/submissions 